\title{
身体がない仮想現実環境において歩行と視点移動の同期が臨場感を伴う
}

\author{
西山 雄大, 植林 尚之, 野村 収作
}

長岡技術科学大学

\section{Movement Consistency between Walk and Viewpoint is Accompanied with Feeling of Presence in a Virtual Reality Environment where a Body is not Presented}

\author{
Yuta NISHIYAMA, Naoyuki UEBAYASHI and Shusaku NOMURA \\ Nagaoka University of Technology, 1603 Kamitomioka, Nagaoka, Niigata 940-2188, Japan
}

\begin{abstract}
In a virtual reality (VR) environment, users often control virtual bodies. While having a body is likely to promote a feeling of presence, does an invisible body make users lose the feeling? Using a head mounted display and 360-degree camera shooting pseudo image, we constructed a situation where participants can walk "with an invisible body." The camera was moved in accordance with the participant's walking and was hung at the height of the participant's line of sight, so the participants felt walking in the virtual space freely. We tested a feeling of presence in the proprietary developed VR with/without obstacle in the image and found that the feeling of presence was maintained even in the situation when they virtually "transmitted" the obstacle. Our findings suggest that consistent somatosensory-vestibular-visual stimuli during walking are accompanied with the feeling of presence even when a body was not presented.
\end{abstract}

Keywords : Invisible body, Walking, Virtual reality

\section{1.はじめに}

ここ数年, 精密なヘッドトラッキング機能を有する種々の ヘッドマウントデイスプレイ(HMD) が市販されるようになり, 仮想現実 $(\mathrm{VR})$ に抢けるユーザーの没入感は飛躍的に向上 した [1]．高機能のHMDを用いることで，ユーザーは“いま ここに居るという感覚”（以降これを「臨場感」と呼ぶ）を強く 感じることができる，VRでは，しばしばアバターやハンド トラッキングのような仮想身体により仮想環境内における ユーザー自身の “存在”を明示することも多い [2]. 当たり前 のことだが，実世界では自身の身体がないという状況は想像す ら難しく [3]，より実世界と同じように振る舞えるVR環境を 志向するとき，仮想身体を想定することは自然なことである.

一方, 最近の神経学的研究では, 被験者の身体とそれを 模した模型に対して多感覚同期的な刺激を与えるという実験 パラダイムを導入し，自己の身体とその認識との関係性につい て研究がなされてきた $[4,5]$. 例えば, ゴムの手錯覚 (Rubber Hand Illusion）の実験では, 被験者はゴムでできた偽物の 手が実験者に“触られる”様子を見ながら，実際に自分の手 (被験者は自分の手を直接目視できないように置かれている) が実験者により同期的に刺激されると, 被験者はゴムの手が あたかも自分の身体の一部であるように感じる $[6]$ ，こうし た模型に対して自身に帰属していると感じる感覚は「所有感 (Sense of Ownership)」と呼ばれ $[4,7]$, 自己意識と身体的 特徵 (形状・質感)を強く関連付ける感覚とされている $[5,8]$. しかしながら, 最近の研究では, 自身の身体が“視覚的に
存在しない”状況であっても多感覚同期刺激により所有感が 生じることが報告されている [9-11]。つまり, 所有感は身体 に基づく自己意識に関わる感覚であるものの, 必ずしも身体 的特徵そのものに隷属している訳ではないと考えられる. その様に考えた場合，VR空間においてハンドトラッキングの ような身体表現やアバターのような仮想身体が無くとも Sense of Ownership としての所有感は生まれるかもしれない. また, そうした所有感はVRがもたらす臨場感そのものに対しても 強く関連しているのかもしれない.

以上の研究動機に基づき, 本研究では“視覚的に身体が存 在しない状況で歩行する”という状況をVRと実空間の歩行 により構成し, 心理的な臨場感が伴われるか否かを検証した。 つまり, 歩行動作による体性感覚·前庭感覚のフィードバック, およびそれらに整合的な視点移動の多感覚同期刺激により, 身体の存在しないVRにおいても「臨場感」が伴うか否かを 検証した。

\section{2. 実 験 手 法}

前節に述べた研究目的に対し, 本研究では, HMDを用いて 視覚的に身体がない状況で歩行できる環境を構築した (図 1 (a)).HMDには実験参加者にとって既知の場所が投影

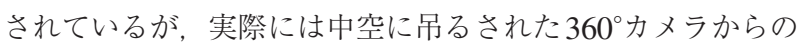
ライブ映像のため，参加者は自身の身体が見えず視点のみが 宙に浮いているような状況になっている。この状況で参加者 には歩行動作を行ってもらうが, その際 $360^{\circ}$ カメを参加者 の歩行に合わせて動かすことで，被験者はあたかも自分自身 
が歩行して視点が動いている（なおかつ自身の身体は存在し ない)ように感じる。この実験系を用い, HMDを装着して 歩く試行を 2 種（障害物あり・なし，ささらにHMDを未装着 で歩く試行を 1 種行った。

\section{1 実験参加者}

健常成人男性 18 名 (年齢 19-23歳, 平均 21 歳) が実験に 参加した。実験内容の説明の後, すべての参加者が実験参加 同意書に署名した，本研究はヘルシンキ宣言の原則に則り， 長岡技術科学大学倫理委員会の承認を得て実施された。

\section{2 実験条件: 通常歩行 (Normal), HMD通常歩行 (HMD_norm), HMD障害物歩行 (HMD_obst)}

参加者は歩行エリアまたはHMDエリアを歩く(図 1 (a)). 実験条件は次の3 種ある。1)「通常歩行」では, 参加者は HMD を装着せずに歩行エリアを歩く（図1（b)）。これに対し， 2)「HMD通常歩行」では, 参加者はHMD (Oculus Rift cv1, Oculus VR, LLC, U.S, 解像度 $2160 \times 1200$ pixel, 視野角 $\left.110^{\circ}\right)$ を装着してHMDエリアを歩く（図1 (c))。このときHMDに 投影される映像は歩行エリアである。つまり, 実際には参加 者はHMDエリアで歩くが, その歩行に合わせて, 視覚的に は歩行エリアのスタート地点からゴール地点まで歩いている ような映像が投影される。 2)「HMD障害物歩行」はHMD 通常歩行と同様だが, 歩行エリアの中間地点に障害物（ダン ボール箱W500, D750, H625 mmを3 個設置) が置かれている (図 $1(\mathrm{~d})$ ). 実際に障害物が置かれているのは歩行エリア内のみ であり, 中空カメラはその上を通過することができるため, 参加者の視覚的にはあたかも障害物をすり抜けるような映像 刺激となる。

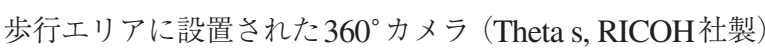
は, 歩行エリアの $2.5 \mathrm{~m}$ 上空を通るレール（スタート地点と
ゴール地点を結ぶ）から吊り下げられており，レンズの高さ は各参加者の直立時の目の高さに調節された，HMDに投影さ れるライブ映像はカメラ位置で全方向取得されており, 参加 者は歩行エリア内で自然に周囲を見回すことができる，参加 者には，HMDを装着した時点で周囲を見回すよう指示した。 さらに，見下ろした際に自身の身体が視覚的には無いことを 確認させた.

2 種類の HMD歩行条件では, 訓練された実験者がカメラ の水平位置を参加者の移動に合わせて手動で動かした，尚， 「HMD障害物歩行条件」では，映像内の歩行経路に障害物 (段ボール箱) があるが, 参加者はそれを“無視して”直進する よう教示された，カメラは箱の上空を通り過ぎることができ るため, 参加者は視覚的に障害物をすり抜けることができる.

\section{3 実験手順}

参加者は実験中に行う動作を歩行エリアで練習した後, 3 条件それぞれについて 10 分程度の実験ブロックを 3 セット 同日に実施した (参加者内実験計画)。ブロックの実施順序 はカウンターバランスを考慮した。実験中，参加者には白色 雑音が流れるノイズキャンセリング機能ヘッドホンを装着さ せ，マイク入力による実験者の指示のみが与えられた。

実験条件は前節の3 種だが, 参加者が行う動作は共通して いる。まず参加者は閉眼のままスタート地点（通常歩行では $\mathrm{A}$ 地点, 両 $\mathrm{HMD}$ 歩行ではB 地点：図 $1(\mathrm{a}))$ に誘導され, 進行 方向へと身体の向きを調整される。次に参加者は目を開け ゴール地点（看板で示される）まで直進するよう指示される. その際，歩幅や速さについては，できるだけ普段通りに歩く よう教示された.ゴール地点に着くと再び目を閉じ, 後述の 歩行時間の報告を行うと 1 試行が終了する．以上の試行を各 条件について10回ずつ, エリア内を往復するように実施した。 全試行終了後，参加者は質問表に回答した. (a)

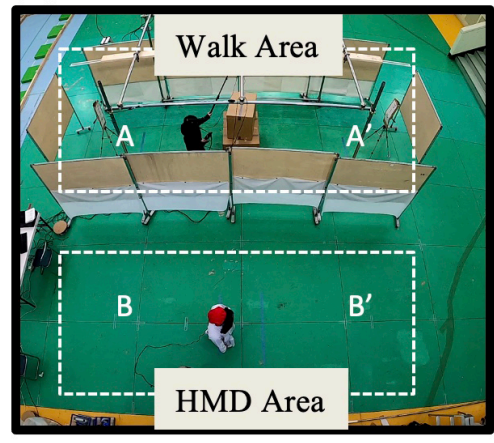

(b)

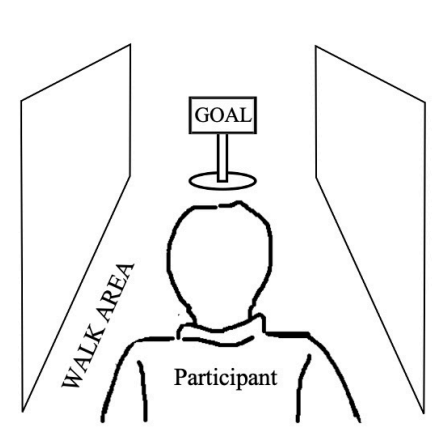

(c)

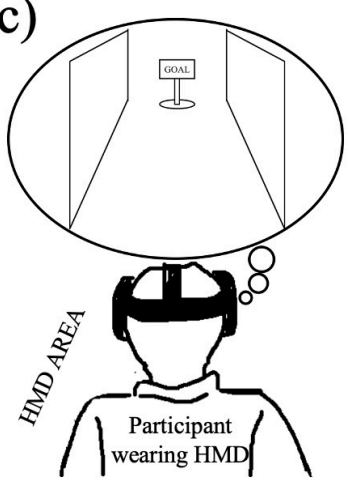

(d)

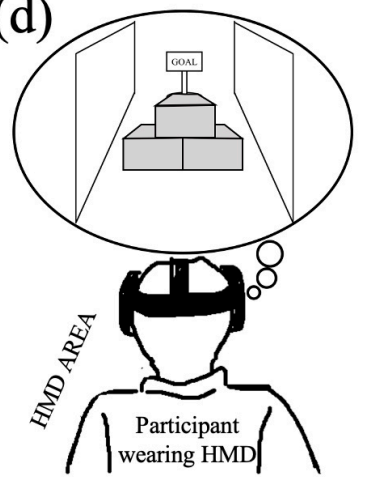

図1 実験環境と3 種の実験条件

（a）実験環境の俯筒写真. 参加者は実験条件によりスタート位置 $A$ または $B\left(A^{\prime}, B^{\prime}\right.$ は復路時）からゴ一ル位置（スタート位置から $5 \mathrm{~m}$ 前方に看板設置) まで直進する.（b）「通常歩行」条件では，参加者はHMDを装着せず歩行エリアを歩く（（c）「HMD通常歩行」 条件では, 参加者はHMDを装着しHMDエリアで歩く、ただし，HMDには歩行エリアのライブ映像が投影されるため，参加者は歩 行エリアで歩いているような視覚刺激を与えられる. (d)「HMD障害物歩行」条件では, 投影された歩行エリアに障害物が置かれて いる. ただし, 障害物の実体はカメラ (視点) の置かれた歩行エリアにあり, 参加者が歩くHMDエリアにはないため, 参加者は視覚 的に障害物をすり抜けることができる. 


\section{4 評価指標}

(1) 歩行時間

各試行において客観的および主観的歩行時間を評価した. 客観的歩行時間は試行ごとに実際に参加者が歩いてゴールま で到達するまでの時間である.さらに主観的歩行時間として 参加者自身がゴールに到達した直後にその試行で自分が歩い た時間（秒）をストップウォッチにより見積もらせた.

(2) 歩行軌跡

$\mathrm{HMD}$ 装着時の歩行軌跡を床上高さ $6 \mathrm{~m}$ に設置されたビデオ カメラ (Gopro Hero8, Woodman Labs 社製. Camera mode 2.7K $4: 3$ 60fps Wide Lens) により記録・評価した。記録さ れた映像の歪み補正を行った後, フレーム毎に参加者の頭部 位置を取得した，参加者間の身長差による誤差を排除するた め, 各参加者の身長から推定される地面位置での座標を算出 した [12]. この座標データから, 参加者の進行角度変化の標 準偏差を算出した.

(3) 心電図

ワイヤレス生体計測装置 (Polymate Mini, 株式会社ミユキ 技研）を用いて歩行中の心電図を計測し, 計測波形から R-R間 隔に基づく瞬時心拍数を求めた (Acqnaledge4.1, BIOPAC 社). 尚, 心拍数は zスコアを用いて標準化した。

(a)

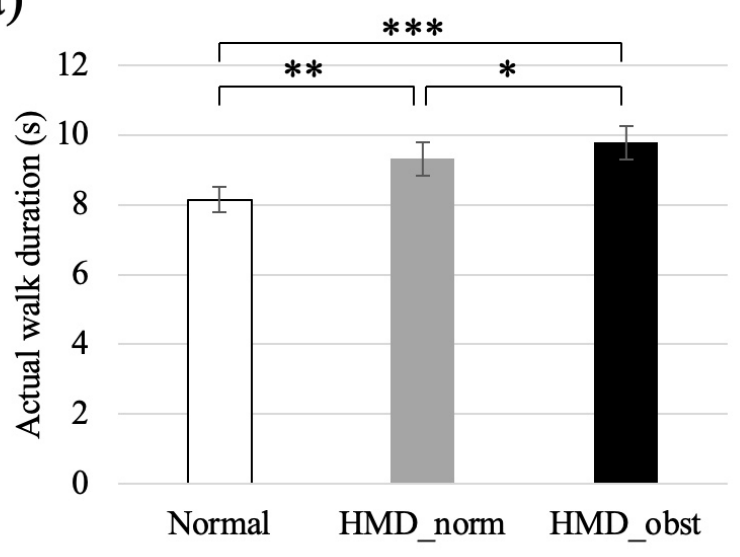

(b)

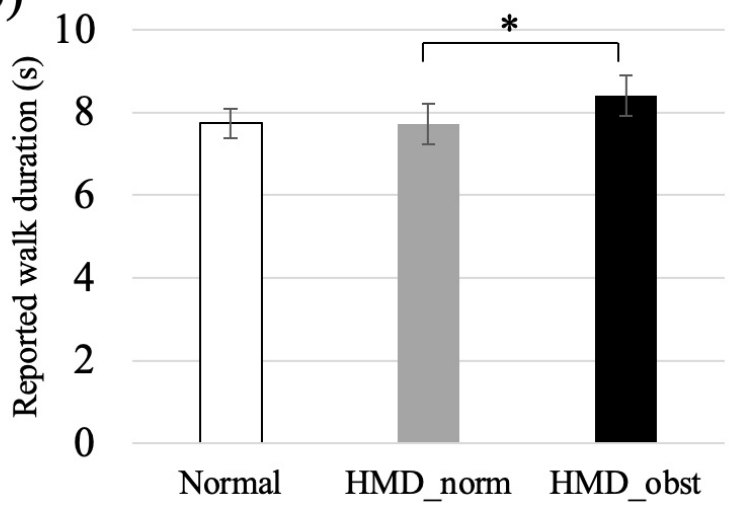

図2（a）実際の歩行時間 (客観的歩行時間).（b）参加者が歩行 直後に報告した歩行時間 (主観的歩行時間)

エラーバーは標準誤差を示す. * $p<.05,{ }^{* *} p<.01,{ }^{* \star *} p<.001$

\section{(4) 心理評価}

HMD歩行時の心理的な「臨場感」および能動的な動きの 自覚 (「主体感」: Sense of Agency [13]) に関して，身体認識 に関する先行研究を参考に質問表を作成した $[14,15]$ 。臨場 感は「いまここにいる」という感覚であり，「ここ」に関する 感覚と「いま」に関する感覚に分けて質問項目を設定した。 「ここ」に関する質問として「映像の場所に実際にいるように 感じた」（質問 1）および，「いま」に関する質問として「事前 に録画された映像だと感じた」（質問2）という質問を設けた （ただし，質問2の得点は逆符号表記とした）。またこれとは 別に「主体感」に関する質問として「自ら歩いて視線を移動さ せていると感じた」（質問3）を設けた.

参加者は各HMD歩行の終了後，歩いているときに感じた ことについて，上述の3つの質問にノートパソコンとマウス を用いてヴィジュアルアナログスケール（VAS）(“まったく そう思わない”〜“まったくそう思う”)により回答した。

(5) 統計手法

有意水準を $\alpha=.05$ とし, $t$ 検定を用いて解析した. 通常歩行・ $\mathrm{HDM}$ 歩行 2 種の 3 条件を比較する場合はBonferroni 補正に より $p$ 值を調整した。 な扮心理評価に関して, 機材トラブル により 1 名分のデー夕が損失したため 17 名分のデー夕を解析 した。

\section{3. 結 果}

\section{1 行動様態}

1 試行につき実際に歩いた時間はHMD障害物歩行でもっ とも長く，次にHMD通常歩行，通常歩行の順であった (図2 (a). Normal vs. HMD_norm : $t(17)=4.38, p=.001$; Normal vs. HMD_obst : $t(17)=6.01, p<.001$; HMD_obs vs. HMD_norm : $t(17)=3.29, p<.05)$. また試行直後に参加者 によって報告された歩行時間はHMD障害物歩行がもっとも 長かった（図2 (b). Normal vs. HMD_norm：n.s. ; Normal vs. HMD_obst:n.s.; HMD_obs vs. HMD_norm : $t(17)=3.17$, $p<.05$ ).

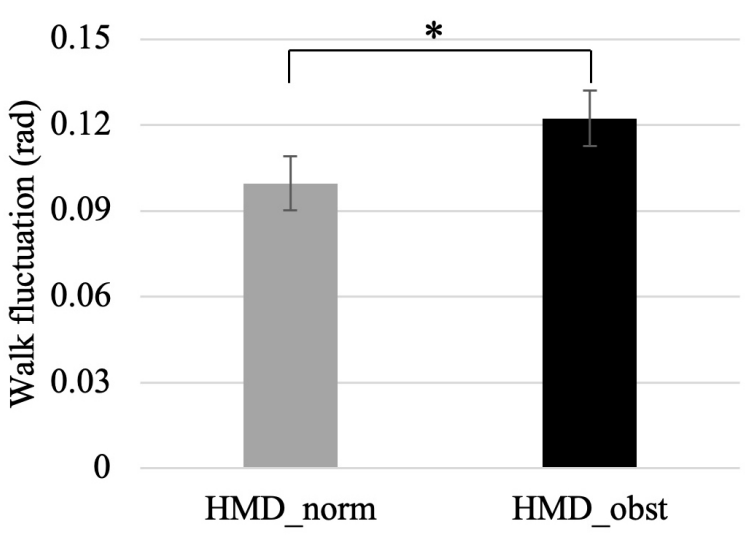

図3 参加者の歩行軌跡から算出された歩行ゆらぎ エラーバーは標準誤差を示す。 ${ }^{*} p<.05$ 
(a)

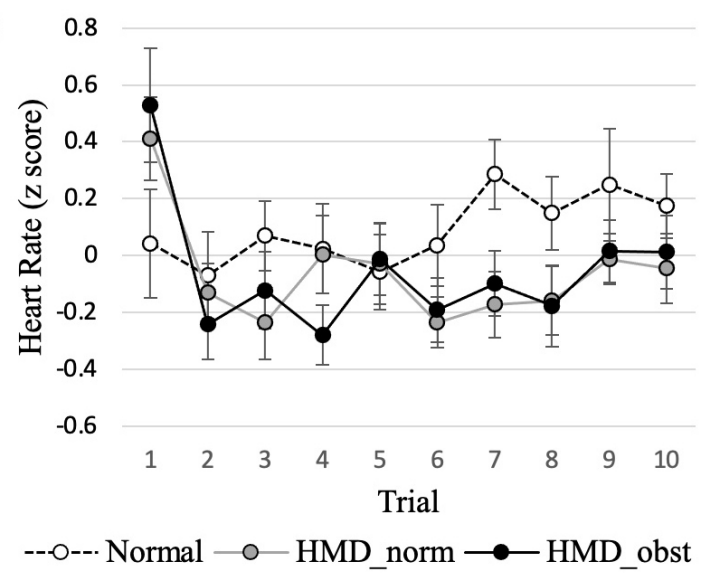

(b)

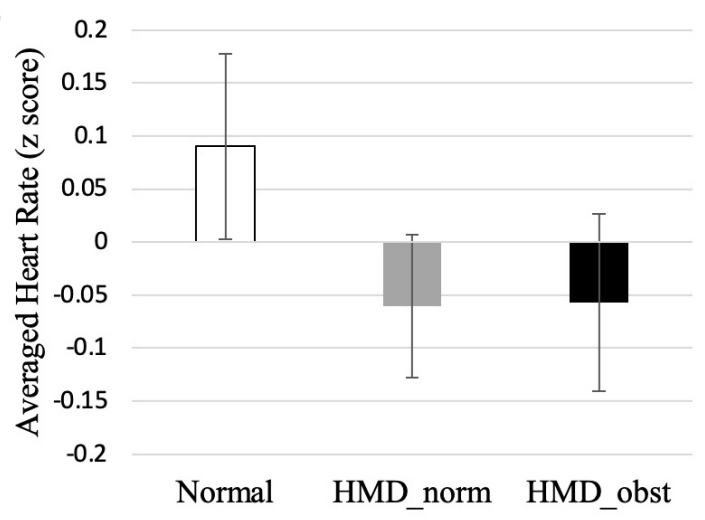

図4 平均心拍数のzスコア

（a）試行ごとの結果.（b）条件ごと平均值.

エラーバーは標準誤差を示す。

歩行のゆらぎ（進行角度変化の標準偏差）はHMD歩行で のみ計測された。条件間で有意な差があり, HMD障害物歩 行でより大きいばらつきを示した（図3.HMD_obs vs. HMD_norm : $t(17)=2.88, p=.01)$.

図 4 は試行ごとの平均心拍数および条件ごとの平均心拍数 を示している. 統計的な差は認められないものの, 全体の傾 向として通常歩行の心拍数がもっとも高かった。また，1回目 の試行においては両HMD歩行条件の心拍数が通常歩行より も高い傾向にあった.

\section{2 心理評価}

「いま」「ここ」という臨場感, そして主体感が扔㧤ね 認められた（図 5. one-sample $t$-test, Q1-HMD_norm： $t(16$ ) $=15.1, p<.001, \mathrm{Q} 1$-HMD_obst $: t(16)=8.54, p<.001$; Q2-HMD_norm : $t(16)=2.16, p<.05$, Q2-HMD_obst $: t(16)$ $=1.27, p=.22 ; \mathrm{Q} 3$-HMD_norm $: t(16)=13.91, p<.001$, Q3-HMD_obst : $t(16)=7.12, p=.001)$. 条件間の比較に注目 すると,「ここ」に関する質問 1 ではHMD通常歩行の得点が

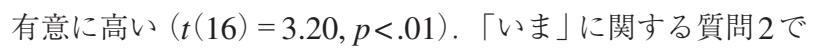
は条件間の得点差はなく, どちらの条件でも個人差が大きく 否定と肯定が同数程度である。主体感に関する質問 $3 て ゙ は$ 条 件間の差はない.

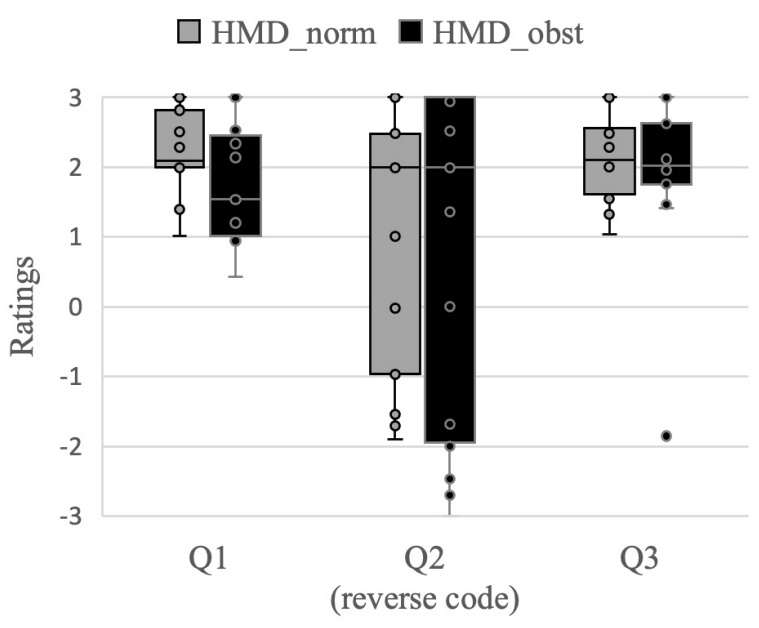

図5 質問表への回答結果

質問 2 の得点は逆符号で示されている．箱の上下端および內線は 四分位数を表し、ひげの上下端は最大值最小值を表す，全データ が点でプロットされており, ひげの外側の点は第一第三四分位数 を基準に四分位範囲の1.5倍を超える外れ值を示す.

\section{4. 考察}

HMDを用いたVR環境において，操作対象となる身体が 提示されない場合,「いまここに居る」という臨場感は損な われてしまうのだろうか?この疑問に対し，本研究では “視覚的に身体が存在しないままに歩行する”という状況を 仮想空間により構築し，その空間に対する心理的な臨場感の 有無を調査した.

実験参加者が装着するHMDには参加者が既に見知った 場所の映像が投影されている。ただし，どこを見てもその 映像中に身体はなく，視点が宙吊りになっている，その状況 で参加者は歩行するよう指示され，なお且つ，進路に障害物 があってもそれを無視して通り抜けるよう求められた。その 結果, 障害物がある場合において, 参加者の歩行時間は客観 的にも主観的にもより遅く，歩行軌跡はより大きいゆらぎを 示した。これは進行方向の障害物に対する行動としてある意 味で自然な反応であるように思える。しかしながら，そのよ うに障害物を認識して行動様態を変化させつつも, 参加者は 障害物をすり抜ける場合でさえ「ここ」という場所に関する 感覚を有し，「いま」という時間に関する感覚も完全に失われ ることはなかった。つまり, “身体が存在しない”という非現 実的なシチュエーションに拈いても尚, 歩行による体性感覚・ 前庭感覚のフィードバック，およびそれらに整合的な視点移 動による多感覚同期刺激がある場合は「臨場感」が伴われる ことが示唆された。

さらに「主体感」についても障害物の有無に関わらず高い得 点を示した，主体感はSense of Agency と呼ばれ，「私が行為 の原因である」と感じることであり，意図した行為が適切に 実行されることで生じる $[13,16]$. 本研究でも歩行するのは 参加者自身であるから, 主体感が高スコアになることは理解 
できる、ただし, 本研究では, 実際には実験者が参加者の動 作に合わせてレールに吊り下げたカメラを手動で移動させて いるため, 参加者の主体的な動作に対し視点移動のずれを完 全になくすことはできない（特に始動停止時の遅れや実際と 映像の進行方向のずれ)，それにもかかわらず，参加者が自ら 視点を動かせていると感じていることは, 歩行と視点移動の 対応づけが頑健であることを示唆している. これは, 歩行時 の主体感が時空間的なずれに頑健であることを示す先行研究 と整合的である，例えば，歩行によってスクリーン上の仮想 身体を操作するVR環境において, 両者の軌跡間に時空間的 なずれ（時間： $210 \mathrm{~ms}$ 以内, 空間 : $10^{\circ}$ 以内）が提示されると きでさえ, 参加者は主体感を感じることができる $[17,18]$. 同研究では, 参加者は無自覚にずれを補償するように動くこ とも示されているが, 本研究で観察されたHMD条件で実際 の歩行時間の伸長は, 視点移動のずれに対する動作補償が影 響しているのかもしれない.

現在, HMDに代表されるVR技術は神経学的研究の重要な 研究ツールに留まらず $[2,19]$, 高度に適応的で制御可能な ッールとして, 身体機能を改善するための理学療法への応用 でもその注目度は増してきている $[20,21]$. このような利用 法において，ユーザーはアバターを操作して作業をこなし， その結果がVR環境内で直ちに反映されるようなリアルタイ ム・多感覚フィードバックが与えられる. 行為の観察は同等 の行為の実行に関わる脳内運動系を克進する [22]ことから, 自身の運動結果の観察と改善の機会が与えられるという点で, このリアルタイムフィードバックの仕組みは重要である。一方, 現実には起こりえないことを可能とするVR技術の利点を 最大限生かすならば，あえてユーザーが意図しても実際には できない動作をVR環境で実現させる仕組みも考えられる. このような物理的な制約を超えた発想は, ユーザーの感性に 着目するからこそ生み出すことができる，本研究では，身体 がなくとも参加者の運動と視点移動の同期は臨場感を伴った. このことを踏まえ，たとえば，あえてアバターを使わず， 意図する動作が環境に与える結果のみを整合的にフィード バックするといった仕組みを構築することで, 実際には運動 が起こらなくとも, 意図と結果の整合性が臨場感を伴い, 逆に実際には働いていない運動系に働きかけることができな いだろうか. そのためには, 歩行によって生じる感覚フィー ドバック自体も実験的に操作するような環境を構築するなど, 臨場感を引き起こすための最小要件を見極めるさらなる研究 が必要となるだろう。以上のように，VR環境中の身体の在り 方をも考慮した臨場感の起源の探求は, 現実世界では味わえ ない臨場感をもたらすシステムという点で感性工学分野への 寄与が期待できる.

本研究には以下の制約がある。まず, 本研究は視覚的に 身体がない場合の障害物への反応を調査したが, HMD着用時 の身体の有無による効果を比較するためにアバターの利用や HMD 前面のカメラ映像による通常視点の歩行など,「身体が ある」条件についても検討の余地がある. さらに, 本研究で は参加者の歩行に視点移動を同期させたが, 特に主体感に
対して参加者の能動性の寄与を確かめるためには, たとえば 車椅子や台車などで受動的に動かされる状況も加えて比較検 討する余地がある。

\section{5. まとめ}

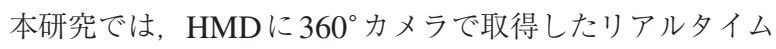
映像を投影することで，視覚的に身体がないVR環境を構築 した、この環境において、ユーザー自らの歩行に合わせて 映像の視点が移動するとき，障害物をすり抜けるような特殊 な状況でさえ心理的な臨場感が伴われるかを調査した。その 結果, 参加者は視覚的に身体が無いと認識しつつ障害物に対 して行動様態を変え, そのうえで心理的には臨場感を感じて いた。このことから，VR環境において視覚的に身体がなく とも, 歩行と視点移動の同期が臨場感をもたらすことが示唆 された。

\section{謝 辞}

本研究はJSPS 科研費JP19K20384の助成を受けて実施さ れた。

\section{参 考 文 献}

[1] Jensen, L., and Konradsen, F.: A review of the use of virtual reality head-mounted displays in education and training. Education and Information Technologies, 23(4), pp.15151529,2018

[2] Sanchez-Vives, M.V., and Slater, M.: From presence to consciousness through virtual reality. Nature Reviews Neuroscience, 6, pp.332-339, 2005.

[3] James, W.: The principles of psychology. Dover, New York, NY., 1890.

[4] Ehrsson, H.H.: Multisensory processes in body ownership. In Multisensory Perception. Academic Press, pp.179-200, 2020.

[5] Blanke, O., Slater, M., and Serino, A.: Behavioral, neural, and computational principles of bodily self-consciousness. Neuron, 88(1), pp.145-166, 2015.

[6] Botvinick, M., and Cohen, J.: Rubber hands 'feel' touch that eyes see. Nature, 391(6669), p.756, 1998.

[7] Kilteni, K., Maselli, A., Kording, K.P., and Slater, M.: Over my fake body: body ownership illusions for studying the multisensory basis of own-body perception. Frontiers in Human Neuroscience, 9, 141, 2015.

[8] Park, H.D., and Blanke, O.: Coupling inner and outer body for self-consciousness. Trends in Cognitive Sciences, 23(5), pp.377-388, 2019.

[9] Guterstam, A., Abdulkarim, Z., and Ehrsson, H. H.: Illusory ownership of an invisible body reduces autonomic 
and subjective social anxiety responses. Scientific Reports, 5, 9831, 2015.

[10] D’Angelo, M., Di Pellegrino, G., and Frassinetti, F.: Invisible body illusion modulates interpersonal space. Scientific Reports, 7(1), pp.1-9, 2017.

[11] Kondo, R., Sugimoto, M., Minamizawa, K., Hoshi, T., Inami, M., and Kitazaki, M.: Illusory body ownership of an invisible body interpolated between virtual hands and feet via visual-motor synchronicity. Scientific Reports, 8(1), pp.1-8, 2018.

[12] Boltes, M., and Seyfried, A.: Collecting pedestrian trajectories, In: Neurocomputing, Special Issue on Behaviours in Video, 100, pp.127-133, 2013.

[13] Chambon, V., Sidarus, N., and Haggard, P.: From action intentions to action effects: how does the sense of agency come about?. Frontiers in Human Neuroscience, 8, 320, 2014.

[14] Longo, M.R., Schüür, F., Kammers, M.P., Tsakiris, M., and Haggard, P.: What is embodiment? A psychometric approach. Cognition, 107(3), pp.978-998, 2008.

[15] Gonzalez-Franco, M., and Peck, T.C.: Avatar embodiment. Towards a standardized questionnaire. Frontiers in Robotics and AI, 5, 74, 2018.

[16] Wolpert, D. M., Ghahramani, Z., and Jordan, M. I.: An internal model for sensorimotor integration. Science, 269(5232), pp.1880-1882, 1995.

[17] Kannape, O.A., Schwabe, L., Tadi, T., and Blanke, O.: The limits of agency in walking humans. Neuropsychologia, 48(6), pp.1628-1636, 2010.

[18] Kannape, O.A., and Blanke, O.: Self in motion: sensorimotor and cognitive mechanisms in gait agency. Journal of Neurophysiology, 110(8), pp.1837-1847, 2013.

[19] Herbelin, B., Salomon, R., Serino, A., and Blanke, O.: Neural mechanisms of bodily self-consciousness and the experience of presence in virtual reality. Human Computer Confluence, pp.80-96, 2016.
[20] Kannape, O.A., Barré, A., Aminian, K., and Blanke, O.: Cognitive loading affects motor awareness and movement kinematics but not locomotor trajectories during goal-directed walking in a virtual reality environment. PloS one, 9(1), e85560, 2014.

[21] Howard, M.C.: A meta-analysis and systematic literature review of virtual reality rehabilitation programs. Computers in Human Behavior, 70, pp.317-327, 2017.

[22] Fadiga, L., Fogassi, L., Pavesi, G., and Rizzolatti, G.: Motor facilitation during action observation: a magnetic stimulation study. Journal of neurophysiology, 73(6), pp.2608-2611, 1995.

西山 雄大 (非会員)

2012 年 神戸大学大学院理学研究科博士後期課程修了. 同年 新潟 大学超域学術院特別研究員. 2014 年 大阪大学産学連携本部特任 助教. 2017 年長岡技術科学大学工学部講師. 理論生命科学, 内部観測. 博士 (理学).

y-nishiyama@kjs.nagaokaut.ac.jp

植林 尚之 (非会員)

2018 年 熊本高等専門学校機械知能システム工学科卒業. 2020 年 長岡技術科学大学工学部情報・経営システム工学課程卒業.

野村 収作 (正会員)

2001 年 神戸大学大学院自然科学研究科博士後期課程修了．同年 室蘭工業大学PD. 2003 年 島根大学総合理工学部助手. 2008 年 長岡技術科学大学産学融合トップランナー養成センター特任准 教授. 2020 年 同大学工学部教授. アンビエント生体医工学研究 に従事. 博士 (理学). 